\title{
ANXIETY AND DEPRESSION SCORES IN PATIENTS WITH BURNING MOUTH SYNDROME
}

\author{
Miroslav Sikora $^{1}$, Željko Verzak ${ }^{2,3}$, Marko Matijevićc ${ }^{1}$, Aleksandar V̌̌ev ${ }^{4}$ Stjepan Siber $^{1}$, \\ Larisa Musić ${ }^{5}$ \& Andreja Carek ${ }^{6}$ \\ ${ }^{1}$ Department of Dental Medicine, Faculty of Medicine, University of Osijek, Osijek, Croatia \\ ${ }^{2}$ Department of Paediatric and Preventive Dentistry, School of Dental medicine, University of Zagreb, Croatia \\ ${ }^{3}$ University Hospital Centre Zagreb, Zagreb, Croatia \\ ${ }^{4}$ Department of Internal Medicine, Family Medicine and History of Medicine, Faculty of Medicine, \\ University of Osijek, Osijek, Croatia \\ ${ }^{5}$ Department of Periodontology, School of Dental Medicine, University of Zagreb, Zagreb, Croatia \\ ${ }^{6}$ Department of Fixed Prosthodontics, School of Dental medicine, University of Zagreb, Zagreb, Croatia
}

received: 18.12.2017;

revised: 15.3.2018;

accepted: 17.4 .2018

\section{SUMMARY}

Background: Burning mouth syndrome is a condition of unknown etiology, characterized by burning symptoms on the otherwise clinically healthy oral mucosa. Central and/or peripheral neuropathy is one of the proposed causes for this condition. Psychological component in these patients is also very present, as it is known that BMS patients exhibit high levels of pain, anxiety, and depression. The aim of this study was to evaluate anxiety and depression among patients with burning mouth syndrome and a control group. We also further review and discuss the literature available on this subject.

Subjects and methods: A total of 93 subjects, divided into two groups, participated in this study. The group of patients with BMS included 43 participants, while the control group consisted of 50 participants. Self-reported STAI (State anxiety and Trait anxiety) and BDI questionnaires were used to evaluate anxiety and depression in subjects in both groups.

Results: BMS group had higher average total scores of state anxiety, trait anxiety and depression. The difference between the BMS group and control group was statistically significant for state anxiety scores and BDI scores.

Conclusion: We might conclude that BMS patients are more anxious (state) and depressed when compared with the control group. However, they do not differ from the control group regarding anxiety as a trait. Thus we might conclude that feeling of anxiety in general starts after the BMS symptoms first occur and last for a longer period of time.

Key words: burning mouth syndrome - anxiety - depression

$* * * * *$

\section{INTRODUCTION}

It is well-known that patients with certain dermatological diseases such as psoriasis (Zeljko-Penavic et al. 2013) as well as oral diseases such as burning mouth syndrome, oral lichen planus and recurrent aphthous ulceration have strong involvement of psychological cofactors (Gruden et al. 2009). Burning mouth syndrome (BMS) affects mostly postmenopausal women and is characterized by burning symptoms on the otherwise healthy oral mucosa, usually on the tongue, lips and palate. Despite extensive studies, no single cause and treatment have been determined. Most researchers do agree that there is a central and/or peripheral neuropathic underlying disturbance in BMS patients, however psychological component in these patients is also very present. It is known that BMS patients have high levels of pain, anxiety, and depression (Klasser et al. 2016). It's been hypothesized whether certain psychiatric characteristics, e.g. anxious characteristics, personality disorder or somatization play an underlying role in the development of this condition or BMS itself causes secondary psychiatric symptoms (Schiavone et al. 2012).
Association between BMS and psychological/ psychiatric disturbances has been studied for almost 30 years. Van der Ploeg et al. in the year 1987 reported that in a large number of patients with glossodynia (a total number of 184 BMS patients), psychological aspects such as anxiety, depression, and neurotic tendencies are of great importance (Van der Ploeg et al. 1987). In the same year, Browning et al. analysed 25 BMS patients and found psychiatric disorders in 44\% (11/25) of BMS patients in comparison to the $16 \%(4 / 25)$ of the controls (Browning et al. 1987). Hammarén and Hugoson analysed 18 BMS patients, majority (14/18) of which had psychological or psychological and somatic causes of the symptoms, and stated that most of the patients had suffered extreme traumatic events in the form of deceased, injured and/or handicapped children or prolonged social problems (Hammarén \& Hugoson 1989). Lamey and Lamb investigated 74 BMS patients and the results revealed prevalence of anxiety to be higher than depression in BMS patients (Lamey \& Lamb 1989). Rojo et al. reported that a psychiatric diagnosis was established in 51.35\% (38/74) of BMS patients, and that the depression was the predominant 
disorder, yet anxiety, if present, greatly influenced the psychiatric condition of BMS patients (Rojo et al. 1993). Trombelli et al. reported that anxiety was the predominant psychological symptom among $2 / 3$ of BMS subjects that had present psychological factors (Trombelli et al. 1994). In a study by Bergdahl et al., in comparison with a control matched group, BMS patients scored significantly less in socialization scale and significantly higher in somatic anxiety, muscular tension, and psychasthenia scales, also showing impaired psychologic functioning. (Bergdahl et al. 1995). Furthermore, 25 patients with glossodynia were evaluated in regard of personality characteristics and psychopathology and the results of that study showed that hostility and possibly depression are important psychological profile components in these patients (Trikkas et al. 1996). A smaller study of 20 BMS patients rated majority of the subjects as alexythimic, meaning having difficulty with describing and identifying feelings, which suggests somatization should be taken into account during clinical evaluation and treatment of BMS patients (Jerlang 1997). Bogetto et al. reported that even though $1 / 4$ of the BMS patients part-taking in the study did not have any other lifetime psychiatric diagnosis, they showed high rates of comorbid psychiatric diagnoses, such as depression and anxiety (Bogetto et al. 1998), while another study confirmed that depression, anxiety, but also inadaptability and emotional instability were widely present in BMS patients (Pokupec Gruden et al. 2000).

In a study of 10 patients with BMS, after an interview and assessment by a psychiatrist, 6 individuals received a psychiatric diagnosis, suggesting high psychiatric morbidity prevalence in this oral condition (Nicholson et al. 2000), while another study reported at least one personality disorder in more than $85 \%$ of BMS patients (Maina et al. 2005). Al-Quran investigated 32 patients with BMS and found out that the neuroticism (including anxiety and depression) were significantly present in BMS patients in comparison with the matched control subjects (Al Quran 2004). Soto-Araya et al. investigated an association between psychological disorders and the presence of BMS, but also another two oral conditions, oral lichen planus and recurrent aphthous stomatitis. They reported that depression is particularly high in BMS patients, while levels of anxiety are higher in all three groups of patients in comparison with a control matched group (Soto-Araya et al. 2004). BMS patients exhibit higher anxiety scores, but also salivary cortisol levels when compared with the control group (Amenábar et al. 2008). Buljan et al. investigated an association between anxiety and depression in BMS patients and have reported that patients with BMS symptoms showed more significant level of anxiety and depression when compared to the controls. Furthermore, the same authors investigated the correlation between the intensity of BMS symptoms and intensity of the symptoms of anxiety and depression and reported positive correlation between the two (Buljan et al. 2008).
Only two studies reported no psychiatric or psychological disturbances in BMS patients. Carlson et al. reported no evidence for significant depression, anxiety, and somatization in BMS patients. Only a smaller number of evaluated subjects $(7 / 33-21 \%)$ showed a likelihood of psychologic distress. Interestingly, significantly fewer disruptions in normal activities of BMS patients were shown in comparison with a large sampled group of patents with chronic pain (Carlson et al. 2000). Another study evaluated personality of 28 BMS patients and 24 matched controls and reported no significant differences between the two groups(Merigo et al. 2007).

American Psychological Association (APA)_classifies anxiety as an emotion characterized by feelings of tension, worried thoughts and physical changes. Contrary to this, anxiety disorder requires psychiatric attention. The same is also true for depression which can be a symptom but also the disease which requires psychiatric help. (http://www.apa.org/topics/anxiety/).

State-Trait Anxiety Inventory (STAI) actually classifies patients who have anxiety as a trait, i.e. personality characteristic while anxiety as a state reflects current anxious state of the person (Kvaal et al. 2005). Beck Depression Inventory (BDI) is a self-reported instrument that measures attitudes and symptoms characteristic of depression (Beck et al. 1961).

The aim of this study was to evaluate anxiety and depression among patients with burning mouth syndrome and a matched control group.

\section{SUBJECTS AND METHODS}

A total of 93 subject participated in this study. They were divided into two groups. The group of patients with BMS included 43 participants (average age 63.98 y; 48 females, 3 males), while the control group included 50 participants (average age 60.22 y; 35 females, 14 males, 1 unknown). All patients were recruited at the Department of Oral Medicine, School of Dental Medicine in Zagreb and were clinically evaluated by the attending oral medicine specialists upon reporting to the Department with various complaints. For the BMS patients inclusion criteria were symptoms of burning in the oral cavity with otherwise clinically healthy appearance of the oral mucosa. Control group consisted of patients reporting to the Department of Oral Medicine for various oral conditions but with no burning mouth symptoms. All study participants signed an informed consent for the participation in the study.

STAI and BDI questionnaires were used to evaluate anxiety and depression in subjects in both groups. STAI (State-Trait Anxiety Inventory) questionnaire is used to diagnose and measure state and trait anxiety and also to distinguish it from depressive syndromes (Spielberger et al. 1983). This self-reported questionnaire contains of 40 items, 20 of which assess state anxiety and 20 assess trait anxiety. Each item is rated on a four point scale (14 ), from not being anxious at all to being anxious very 
much about the item in question, thus the higher test scores indicate a higher level of anxiety. State anxiety items include „I feel at ease“, and „I feel upset“" and are meant to evaluate the subject's feeling right now (in that moment). Trait anxiety items include „I feel nervous and restless“ and „I feel satisfied with myself“ and are meant to rate how a person generally feels, for a prolonged period of time. For state anxiety score results 3940 have been suggested to detect clinically significant symptoms of anxiety, though higher scores (54-55) for adults have been suggested by other authors (Kvaal et al. 2005). BDI (Beck Depression Inventory) is a selfreported instrument that measures attitudes and symptoms characteristic of depression (Beck et al. 1961). It consists of 21 items and each item is rated from zero (0) to three (3). Total BDI item score can range from 0-63. Total score up to 13 suggest none or minimal symptoms of depression, 14-19 mild symptoms, 20-28 moderate symptoms, while 29 or more suggest severe symptoms of depression. Qualified psychologist analyzed the questionnaires.

Gathered data were processed in Microsoft Excel. Quantitative variables were analyzed by mean and standard deviation, and independent sample t-tests were used to compare the means of quantitative variables between the BMS and control group. $\mathrm{P}$ value of $\leq 0.05$ was considered as statistically significant.

\section{RESULTS}

State anxiety STAI scores are shown in the Table 1. A statistically significant difference in state anxiety STAI scores between the BMS and control group was found, implicating greater ,in the moment ${ }^{\text {“ }}$ anxiety among BMS patients. As seen from the Trait anxiety STAI scores, shown in the Table 2., even though average total STAI score is higher among BMS patients, statistically significant difference between the two groups was not found.

Analysis of the BDI scores has shown a statistically significant difference in the scores of the BMS and control group, as seen from Table 3. Mean total BDI score 13.1 of the BMS group suggests that these patients are experiencing minimal or mild symptoms of depression, while the subjects in the control group, mean total BDI score 8.8 , are categorized among those with minimal or no symptoms of depression.

\section{DISCUSSION}

Although extensive research has already been done about the role of psychiatric disorders in pathogenesis of BMS, it is still unknown whether burning symptoms preceede depression and/or anxiety or it is vice versa. Adamo et al. investigated 50 BMS patients and concluded that these patients had increased tendency of sleep disturbances, anxiety, and depression when compared to the controls (Adamo et al. 2013). Based on the results obtained form 282 patients with BMS who were compared to the 82 patients with trigeminal neuralgia $(\mathrm{TN})$, Komiyama et al. concluded that patients with BMS had 3.8 times higher somatization scores when compared to the patients with TN. The same authors concluded that in BMS patients should receive pain control at the level of central nervous system or to target their psychosocial characteristics (Komiyama et al. 2012). Schiavone et al. showed that pain was affected by depression, and depression is affected by anxiety. BMS patients had increased

Table 1. State anxiety STAI scores for BMS and control groups

\begin{tabular}{lccc}
\hline & Number of subjects & Mean total STAI score & SD \\
\hline BMS group & 42 & 44.9286 & 12.64601 \\
Control group & 50 & 38.4800 & 11.88420 \\
\hline & $\mathrm{t}$ & $\mathrm{p}$ & \\
\hline State anxiety & 2.518 & 0.014 \\
\hline
\end{tabular}

Table 2. Trait anxiety STAI scores for BMS and control groups

\begin{tabular}{lccc}
\hline & Number of subjects & Mean total STAI score & SD \\
\hline BMS group & 43 & 42.8140 & 13.11716 \\
Control group & 50 & 39,8400 & 10,62988 \\
\hline & $\mathrm{t}$ & $\mathrm{p}$ & \\
\hline Trait anxiety & 1.189 & 0.238 \\
\hline
\end{tabular}

Table 3. BDI scores for BMS and control groups

\begin{tabular}{lccc}
\hline & Number of subjects & Mean total STAI score & SD \\
\hline BMS group & 41 & 13.0976 & 9.00501 \\
Control group & 50 & 8.8000 & 8.19407 \\
\hline Depression & $\mathrm{t}$ & $\mathrm{p}$ & \\
\hline
\end{tabular}


anxiety, depression and somatization scores as well as hostility dimensions when compared to the control group. The same authors stated that anxiety could determine a secondary demoralization in BMS patients (depression) and therefore, depressive symptoms could contribute to pain which itself might be somatic feature of depression (Schiavone et al. 2012). De Souza et al. investigated 30 BMS patients and reported that they had a higher frequency of current major depressive disorder, past major depressive disorder, generalized anxiety disorder, hypochondria and cancerophobia. Furthermore, generalized anxiety disorder significantly correlated with current major depression and social phobia and cancerophobia significantly correlated with hypochondria. Patients with BMS had higher scores in Hamilton Rating Scale for Depression (HRSD), Beck Depression Inventory (BDI), State-Trait Anxiety Inventory (STAI) and Dutch Fatigue Scale (DUFS) $(\mathrm{p}<0.05)$ (de Souza et al. 2012). Pokupec et al. conducted study on 120 BMS patients suffering from stomatopyrosis and a diagnosed psychological disturbance. Subjects were divided into 4 groups, undergoing different treatments: 1) antidepressants, 2) anxiolytics, 3) autogenic training and 4) control group. Antidepressants and anxyiolitic drugs had an important role in management of this condition as the psychological tests showed decrease in anxiety of 7.5\%$8.8 \%$, while depression in some of the tested groups completely disappeared. The authors concluded that autogenic trainings is the therapy of choice as it both eliminates the problems and emotionally rehabilitates the patient (Pokupec et al. 2012). Kenchadze et al. analysed 39 BMS patients and reported that three main categories were found. Chronic somatoform dysfunction (23 cases), chronic vegetative disorders (8), and chronic pain phenomenon (12) were identified as well as a paranoid syndrome in one patient (Kenchadze et al. 2012). The same authors concluded that BMS is a psychosomatic problem rather than a psychiatric disorder. In 46 Japanese BMS patients, Matsuoka et al. found that catastrophizing significantly correlated with pain severity, stress-response, psychological disability, social disability, and handicap. Anxiety was also significantly higher in BMS patients when compared to the healthy controls (Matsuoka et al. 2010). The results of this study showed that BMS group had higher average total scores of state anxiety, trait anxiety and depression. The difference between the BMS group and control group was statistically significant for state anxiety scores and depression scores, which is in concordance with the results of other authors (Adamo et al. 2013, Schiavone et al. 2012, de Souza et al. 2012, Matsuoka et al. 2010). The prevalence of both conditions varies greatly within different studies. One of the main reasons might be the use of different evaluating tools (questionnaires) and number of the subjects parttaking in the studies. Even though the role of the psychological component in this condition is unquestionable, further research is suggested to completely clarify the complex etiology behind burning mouth syndrome.

\section{CONCLUSON}

We might conclude that BMS patients are more anxious (state) and depressed when compared with the control group. However, they do not differ from the control group regarding anxiety as a trait. Thus we might conclude that feeling of anxiety in general starts after the BMS symptoms first occur and last for a longer period of time.

\section{Acknowledgements: None.}

\section{Conflict of interest: None to declare.}

\section{Contribution of individual authors:}

Miroslav Sikora, Marko Matijević \& Stjepan Siber: performed the study;

Željko Verzak, Aleksandar Včev \& Andreja Carek: writing of the paper;

Larisa Musić: statistical analysis.

\section{References}

1. Adamo D, Schiavone V, Aria M, Leuci S, Ruoppo E, Dell'Aversana $G$, et al.: Sleep disturbance in patients with burning mouth syndrome: a case-control study. J Orofac Pain 2013; 27:304-13

2. Al Quran FA: Psychological profile in burning mouth syndrome. Oral Surg Oral Med Oral Pathol Oral Radiol Endod 2004; 97:339-44

3. Amenábar JM, Pawlowski J, Hilgert JB, Hugo FN, Bandeira D, Lhüller F, et al.: Anxiety and salivary cortisol levels in patients with burning mouth syndrome: casecontrol study. Oral Surg Oral Med Oral Pathol Oral Radiol Endod 2008; 105:460-5

4. Beck AT, Ward CH, Mendelson M, Mock J, Erbaugh J: An inventory for measuring depression. Archives of General Psychiatry 1961; 4:561-571

5. Bergdahl J, Anneroth G, Perris H: Personality characteristics of patients with resistant burning mouth syndrome. Acta Odontol Scand 1995; 53:7-11

6. Bogetto F, Maina G, Ferro G, Carbone M, Gandolfo S: Psychiatric comorbidity in patients with burning mouth syndrome. Psychosom Med 1998; 60:378-85

7. Browning S, Hislop S, Scully C, Shirlaw P: The association between burning mouth syndrome and psychosocial disorders. Oral Surg Oral Med Oral Pathol 1987; 64:171-4

8. Buljan D, Savić I, Karlović D: Correlation between anxiety, depression and burning mouth syndrome. Acta Clin Croat 2008; 47:211-6

9. Carlson CR, Miller CS, Reid KI: Psychosocial profiles of patients with burning mouth syndrome. J Orofac Pain 2000; 14:59-64

10. de Souza FT, Teixeira AL, Amaral TM, dos Santos TP, Abreu MH, Silva TA, Kummer A: Psychiatric disorders in burning mouth syndrome. J Psychosom Res 2012; 72:142-6

11. Demange C, Husson C, Poï-Vet D, Escande JP: Burning mouth syndromes and depression. A psychoanalytic approach. Rev Stomatol Chir Maxillofac 1996; 97:244-52 
12. Hammarén M, Hugoson A: Clinical psychiatric assessment of patients with burning mouth syndrome resisting oral treatment. Swed Dent J 1989; 13:77-88

13. http://www.apa.org/topics/anxiety/

14. Jerlang BB: Burning mouth syndrome (BMS) and the concept of alexithymia--a preliminary study. J Oral Pathol Med 1997; 26:249-53

15. Kenchadze R, Iverieli M, Okribelashvili N, Geladze N, Khachapuridze N: The psychological aspects of burning mouth syndrome. Georgian Med News 2011; 24-8

16. Klasser GD, Grushka M, Su N: Burning Mouth Syndrome. Oral Maxillofac Surg Clin North Am 2016; 28:381-96

17. Komiyama O, Obara R, Uchida T, Nishimura H, Iida T, Okubo M, et al.: Pain intensity and psychosocial characteristics of patients with burning mouth syndrome and trigeminal neuralgia. J Oral Sci 2012; 54:321-7

18. Kvaal K, Ulstein I, Nordhus IH, Engedal K: The Spielberger State-Trait Anxiety Inventory (STAI): the state scale in detecting mental disorders in geriatric patients. Int $J$ Geriatr Psychiatry 2005; 20:629-34

19. Lamey PJ, Lamb AB: The usefulness of the HAD scale in assessing anxiety and depression in patients with burning mouth syndrome. Oral Surg Oral Med Oral Pathol 1989; 67:390-2

20. Maina G, Albert U, Gandolfo S, Vitalucci A, Bogetto F: Personality disorders in patients with burning mouth syndrome. J Pers Disord 2005; 19:84-93

21. Matsuoka H, Himachi M, Furukawa H, Kobayashi S, Shoki H, Motoya R, et al.: Cognitive profile of patients with burning mouth syndrome in the Japanese population. Odontology 2010; 98:160-4

22. Merigo E, Manfredi M, Zanetti MR, Miazza D, Pedrazzi $G$, Vescovi P: Burning mouth syndrome and personality profiles. Minerva Stomatol 2007; 56:159-67

23. Nicholson M, Wilkinson G, Field E, Longman L, Fitzgerald B: A pilot study: stability of psychiatric diagnoses over 6 months in burning mouth syndrome. J Psychosom Res 2000; 49:1-2
24. Pokupec JS, Gruden V, Gruden V Jr.: Lichen ruber planus as a psychiatric problem. Psychiatr Danub 2009; 21:514-6

25. Pokupec JS, Gruden Z, Gruden V: The impact of psychological testing on the patients suffering from stomatopyrosis. Coll Antropol 2011; 35:1167-76

26. Pokupec-Gruden JS, Cekić-Arambasin A, Gruden V: Psychogenic factors in the aetiology of stomatopyrosis. Coll Antropol 2000;24:119-26

27. Rojo L, Silvestre FJ, Bagan JV, De Vicente T: Psychiatric morbidity in burning mouth syndrome. Psychiatric interview versus depression and anxiety scales. Oral Surg Oral Med Oral Pathol 1993; 75:308-11

28. Schiavone V, Adamo D, Ventrella G, Morlino $M$, De Notaris EB, Ravel MG, et al.: Anxiety, depression, and pain in burning mouth syndrome: first chicken or egg? Headache 2012; 52:1019-25

29. Soto Araya M, Rojas Alcayaga G, Esguep A: Association between psychological disorders and the presence of Oral lichen planus, Burning mouth syndrome and Recurrent aphthous stomatitis. Med Oral 2004; 9:1-7

30. Spielberger CD, Gorsuch R, Lushene, Vagg PR, Jacobs GA: Manual for the State-Trait Anxiety Inventory. Consulting Psychologists Press, Palo Alto, 1983

31. Trikkas G, Nikolatou O, Samara C, Bazopoulou-Kyrkanidou E, Rabavilas AD, Christodoulou GN: Glossodynia: personality characteristics and psychopathology. Psychother Psychosom 1996; 65:163-8

32. Trombelli L, Zangari F, Calura G: The psychological aspects of patients with the burning mouth syndrome. Minerva Stomatol 1994; 43:215-21

33. van der Ploeg HM, van der Wal N, Eijkman MA, van der Waal I: Psychological aspects of patients with burning mouth syndrome. Oral Surg Oral Med Oral Pathol 1987; 63:664-8

34. Zeljko-Penavić J, Situm M, Babić D, Simić D: Analysis of psychopathological traits in psoriatic patients. Psychiatr Danub 2013; 25:56-9

Correspondence:

Larisa Musić, MD

Department of Periodontology, School of Dental Medicine, University of Zagreb

Gundulićeva 5, 10000 Zagreb, Croatia

E-mail:lmusic@sfzg.hr 